\title{
The metabolic impact of hypoxia exposure in human obesity
}

Citation for published version (APA):

van Meijel, L. J. (2021). The metabolic impact of hypoxia exposure in human obesity: a translational approach. [Doctoral Thesis, Maastricht University]. Maastricht University. https://doi.org/10.26481/dis.20210611lm

Document status and date:

Published: 01/01/2021

DOI:

10.26481/dis.20210611/m

Document Version:

Publisher's PDF, also known as Version of record

\section{Please check the document version of this publication:}

- A submitted manuscript is the version of the article upon submission and before peer-review. There can be important differences between the submitted version and the official published version of record.

People interested in the research are advised to contact the author for the final version of the publication, or visit the DOI to the publisher's website.

- The final author version and the galley proof are versions of the publication after peer review.

- The final published version features the final layout of the paper including the volume, issue and page numbers.

Link to publication

\footnotetext{
General rights rights.

- You may freely distribute the URL identifying the publication in the public portal. please follow below link for the End User Agreement:

www.umlib.nl/taverne-license

Take down policy

If you believe that this document breaches copyright please contact us at:

repository@maastrichtuniversity.nl

providing details and we will investigate your claim.
}

Copyright and moral rights for the publications made accessible in the public portal are retained by the authors and/or other copyright owners and it is a condition of accessing publications that users recognise and abide by the legal requirements associated with these

- Users may download and print one copy of any publication from the public portal for the purpose of private study or research.

- You may not further distribute the material or use it for any profit-making activity or commercial gain

If the publication is distributed under the terms of Article $25 \mathrm{fa}$ of the Dutch Copyright Act, indicated by the "Taverne" license above, 
APPENDIX

SUMMARY 
The drastic increase in the obesity prevalence over the last decades, and the concomitant growth in the incidence of related complications such as cardiovascular diseases, type 2 diabetes mellitus and cancer, calls for alternative treatment strategies. Indeed, lifestyle interventions have been proven to be effective, but large inter-individual differences exist in treatment response and long-term compliance is an important issue, highlighting the need for alternative approaches.

Adipose tissue (AT) dysfunction is one of the hallmarks in the development of obesity-related insulin resistance. Interestingly, oxygen levels in tissues may play a key role in metabolic homeostasis in organs such as the AT, skeletal muscle (SM), liver and gut. Conflicting findings have been reported on $\mathrm{AT} \mathrm{pO}_{2}$ in obesity. We have recently demonstrated that AT $\mathrm{pO}_{2}$ was higher in people with obesity, and was inversely associated with insulin sensitivity. The aim of this thesis was to investigate the effects of normobaric mild intermittent hypoxia $(\mathrm{MIH})$ exposure on the metabolic phenotype of AT, SM, liver and the gut in overweight and obese men. Furthermore, we aimed to gain mechanistic insight in the putative metabolic and inflammatory effects of hypoxia using primary human adipocytes and myotubes. Finally, we examined the effects of hypoxic exercise on glucose homeostasis in overweight and obese men with impaired glucose homeostasis.

In Chapter 2, we reviewed the role of $\mathrm{AT}_{\mathrm{pO}}$ on glucose and lipid metabolism, as well as inflammation. In addition, we discussed the putative effects of lowering $\mathrm{pO}_{2}$ by means of hypoxia exposure on AT as well as whole-body metabolism Interestingly, experimental hypoxia exposure impacts adipocyte function by altering glucose and lipid homeostasis, inflammation and by affecting the expression/ secretion of adipokines. Furthermore, several human intervention studies provided evidence that hypoxia exposure may enhance glucose homeostasis and insulin sensitivity. However, well-controlled studies investigating the effects of hypoxia exposure in overweight and obese humans are scarce, since most studies did not include a control group.

Therefore, in Chapter 3, we performed a single-blind, randomized, cross-over study to investigate the effects of normobaric MIH on tissue-specific insulin sensitivity in 12 overweight and obese men. Participants were randomly exposed to $\mathrm{MIH}$ for 7 consecutive days $\left(15 \% \mathrm{O}_{2}\right.$ for $3 \times 2 \mathrm{~h}$ per day or $21 \% \mathrm{O}_{2}$ (control)), with a 3-6 weeks wash-out period. AT and $\mathrm{SM} \mathrm{pO}_{2}$, fasting and postprandial substrate metabolism, tissue-specific insulin sensitivity and AT/SM gene and protein expression were determined. Mechanistically, we investigated the effects of hypoxia exposure on glucose uptake, gene and protein expression in primary human adipocytes and myotubes. We showed that $\mathrm{MIH}$ exposure decreased systemic $\mathrm{O}_{2}$ saturation and $\mathrm{PO}_{2}$ in both AT and SM. In addition, we demonstrated that MIH exposure increased whole-body carbohydrate oxidation with concomitant increased plasma lactate concentrations compared to normoxia exposure. Furthermore, we found increased 
gene expression of several pathways related to inflammation and carbohydrate/ lipid metabolism in AT. MIH did not alter SM mitochondrial respiration/oxidative capacity, nor did it affectAT, hepatic and peripheral insulin sensitivity. Mechanistically, we demonstrated that hypoxia exposure markedly increased insulin-independent glucose uptake in primary human myotubes, but not in adipocytes, which appears to be mediated at least partially through AMP-dependent protein kinase (AMPK).

Since it has been demonstrated that experimental hypoxia exposure affects various pathways involved in energy metabolism, we next investigated the effects of $\mathrm{MIH}$ exposure on the AT proteome in Chapter 4. Abdominal subcutaneous AT biopsies were taken after 7 consecutive days of $\mathrm{MIH}$ exposure under normoxic, fasting conditions, in the randomized cross-over design study. After protein isolation, proteins were identified and quantified using liquid chromatographymass spectrometry. After correction for blood protein contamination, 1022 AT proteins were identified, from which 123 were differentially expressed compared to normoxia. MIH exposure increased several proteins related to focal adhesion, actin cytoskeleton organization and iron homeostasis, whereas it reduced the expression of proteins related to the biosynthesis of polysaccharides, collagen fibril organization and $\mathrm{NAD}^{+}$dependent processes. Interestingly, amongst the latter are central metabolic pathways, such as the tricarboxylic acid cycle, thereby potentially promoting alternative pathways for energy yield under mild hypoxic conditions. Furthermore, we found that an increased tropomodulin-3 (TMOD3) expression was associated with $\mathrm{MIH}$-induced alterations in AT insulin sensitivity. Indeed, TMOD3 has been previously implicated in insulin signal transduction in AT.

We demonstrate, in Chapter 3 , that MIH exposure substantially decreased SM $\mathrm{pO}_{2}$, a phenomenon which is also observed with SM contraction during physical exercise. Exercise-induced SM contraction promotes the secretion of myokines, which may enhance SM glucose uptake and fatty acid oxidation. Since both $\mathrm{MIH}$ exposure and SM contraction substantially decrease $\mathrm{SM} \mathrm{pO}$, we aimed to investigate whether $\mathrm{MIH}$ exposure affects myokine secretion in Chapter 5. Therefore, differentiated primary human myotubes were exposed to $1 \% \mathrm{O}_{2}$ (mimicking physiological hypoxia in SM), $3 \% \mathrm{O}_{2}$ (physiological normoxia in SM) and $21 \% \mathrm{O}_{2}$ (standard laboratory conditions) for $24 \mathrm{~h}$. Subsequently cell medium was harvested for myokine analysis. Furthermore, we determined plasma concentrations of several myokines in overweight and obese individuals exposed to normobaric $\mathrm{MIH}$ for 7 consecutive days during a high-fat mixed meal test under hypoxic conditions (at day 7), and under normoxic conditions (at day 8, approximately $16 \mathrm{~h}$ after the final hypoxic stimulus), in a randomized cross-over fashion. Interestingly, we demonstrate that in vitro hypoxia exposure $\left(1 \% \mathrm{O}_{2}\right)$ altered the secretion of myokines suggested to be involved in glucose homeostasis, revealing hypoxia as a novel modulator of myokine secretion. More specific, in vitro hypoxia exposure increased secreted protein acidic and rich in cysteine (SPARC) and follistatin-related protein 
(FSTL-1) expression, whereas it reduced the expression of leukemia inhibitory factor (LIF) as compared to $3 \% \mathrm{O}_{2}$. However, 7-day $\mathrm{MIH}$ did not alter plasma myokine concentrations during (at day 7) and subsequent to (at day 8 ) the exposure regimen in overweight and obese men.

High-altitude studies suggest that hypoxia exposure may induce alterations in gut microbiota composition, which may in turn affect host metabolism, but wellcontrolled studies are lacking. Therefore, in Chapter 6, we investigated the effects of normobaric $\mathrm{MIH}$ expression ( $15 \% \mathrm{O}_{2}$, 3x2h per day, 7 consecutive days) compared to normoxia $\left(21 \% \mathrm{O}_{2}\right)$ on gut microbiota composition in overweight and obese men. Using $16 \mathrm{~S}$ rRNA gene amplicon sequencing, we demonstrated that $\mathrm{MIH}$ exposure induced modest changes in fecal microbiota composition in overweight and obese humans, shifting several bacterial families and genera towards higher abundances of strict anaerobic butyrate-producing bacteria. Furthermore, we demonstrated that several of these $\mathrm{MIH}$-induced effects on microbial composition were associated with parameters of glucose and lipid metabolism.

Since hypoxia-induced effects on glucose homeostasis may share similar underlying mechanisms compared with physical exercise, we next explored the synergistic potential of hypoxia and exercise. Thus, we performed a single-blind, randomized, cross-over study to investigate the effects of moderate-intensity hypoxic exercise (HE) on glucose homeostasis in overweight and obese humans with impaired glucose homeostasis in Chapter 7. Ten participants performed moderate-intensity cycling sessions for 4 consecutive days under mild normobaric hypoxia $\left(\mathrm{FiO}_{2}: 15 \%\right)$ or normoxia $\left(\mathrm{FiO}_{2}: 21 \%\right)$ at similar relative exercise intensity ( $2 \times 30 \mathrm{~min} / \mathrm{d}$ at $50 \%$ of maximal heart rate $\left(\mathrm{HR}_{\mathrm{MAX}}\right)$ or $50 \% \mathrm{~W}_{\mathrm{MAX}}$ ), with a wash-out period of 3-6 weeks. Throughout the study, 24h-glucose concentrations and systemic $\mathrm{O}_{2}$ saturation was monitored. At day 5, a mixed-meal test was performed under normoxic conditions, and substrate metabolism was investigated. We demonstrated that $\mathrm{HE}$ performed at similar relative workload intensity as compared to normoxia reduced the systemic $\mathrm{O}_{2}$ saturation compared to NE. Yet, HE did not alter mean 24-h, daytime and nighttime glucose concentrations, or any measures of glycemic variability. Nevertheless, the reduction in systemic $\mathrm{O}_{2}$ saturation by $\mathrm{HE}$ was positively correlated with HE-induced change in mean 24-h and daytime glucose concentrations.

In conclusion, the main findings of this thesis are that $\mathrm{MIH}$ did not alter tissuespecific insulin sensitivity. However, both in vivo and in vitro studies demonstrate potent effects on substrate utilization, pointing towards increased glycolytic metabolism. Furthermore, hypoxic exercise did not alter glucose homeostasis in overweight and obese men with impaired glucose metabolism. Future studies are warranted to investigate the potential of different hypoxia exposure regimens, taken into the duration, frequency and severity of the hypoxic stimulus into account, to 
induce metabolic adaptations. It is worthwhile to examine this in men and women separately, and to investigate the effects of hypoxia exposure in study populations with a different metabolic/inflammatory phenotype. If hypoxia exposure appears to elicit beneficial effects, it might provide a novel therapeutic strategy to prevent or treat obesity-related complications. 
APPENDIX

SAMENVATTING 


\section{Samenvatting}

De drastische toename in de prevalentie van obesitas en de gelijktijdige toename van de incidentie van gerelateerde complicaties zoals hart- en vaatziekten, diabetes mellitus type 2 en kanker in de afgelopen decennia, onderlijnen de vraag om alternatieve behandelingsstrategieën. Heden ten dage is er bewijs dat leefstijlinterventies effectief zijn, maar er bestaan grote interindividuele verschillen in de respons op de behandeling en therapietrouw op de lange termijn, wat de behoefte aan alternatieve benaderingen benadrukt.

Vetweefseldysfunctie omvat een van de kenmerken van de ontwikkeling van obesitas-gerelateerde insulineresistentie. Zuurstofniveaus in weefsels zouden mogelijk een sleutelrol kunnen spelen binnen de metabole homeostase in organen zoals de vetweefsel, skeletspier, lever en darmen. Er zijn tegenstrijdige bevindingen gerapporteerd over vetweefsel zuurstofspanning $\left(\mathrm{pO}_{2}\right)$ bij obesitas Onlangs is aangetoond dat de vetweefsel $\mathrm{pO}_{2}$ hoger is bij mensen met obesitas, en tevens omgekeerd geassocieerd is met insulinegevoeligheid. Het doel van dit proefschrift was om te onderzoeken wat de effecten van blootstelling aan normobare milde intermitterende hypoxie $(\mathrm{MIH})$ op het metabole fenotype van het vetweefsel, de skeletspier, lever en darmen bij mannen met overgewicht en obesitas. Bovendien wilden we mechanistisch inzicht verschaffen in de mogelijke metabole en inflammatoire effecten van hypoxie met behulp van primaire humane adipocyten en myotubes. Tenslotte onderzochten we de effecten van fysieke inspanning onder hypoxische condities op glucosehomeostase bij mannen met overgewicht en obesitas met verminderde glucosehomeostase.

In Hoofdstuk 2 wordt de rol van vetweefsel $\mathrm{pO}_{2}$ op het glucose- en lipidenmetabolisme, evenals op inflammatie toegelicht. Daarnaast beschrijven we de vermeende effecten van $\mathrm{pO}_{2}$-verlaging middels hypoxie blootstelling op het vetweefsel en het metabolisme van het hele lichaam. Experimentele blootstelling aan hypoxie kan de functie van adipocyten beïnvloeden door de glucose- en lipidehomeostase en inflammatie te veranderen, tevens door de expressie en secretie van adipokines te beïnvloeden. Bovendien hebben verschillende humane interventiestudies aangetoond dat blootstelling aan hypoxie de glucosehomeostase en insulinegevoeligheid kan verbeteren. Gecontroleerde onderzoeken naar de effecten van blootstelling aan hypoxie bij mensen met overgewicht en obesitas zijn echter schaars, aangezien de meeste onderzoeken geen controlegroep omvatten.

Daarom hebben we in Hoofdstuk 3 een enkelblinde, gerandomiseerde, crossover studie uitgevoerd om de effecten van normobare MIH op weefselspecifieke insulinegevoeligheid bij 12 mannen met overgewicht en obesitas te onderzoeken. Deelnemers werden willekeurig blootgesteld aan $\mathrm{MIH}$ gedurende 7 opeenvolgende dagen ( $15 \% \mathrm{O}_{2}$ gedurende $3 \times 2$ uur per dag of $21 \% \mathrm{O}_{2}$ (controle)), met een uitwasperiode van 3-6 weken. Vetweefsel en skeletspier $\mathrm{pO}_{2}$, nuchtere 
en postprandiaal substraatmetabolisme, weefselspecifieke insulinegevoeligheid en gen- en eiwitexpressie werden bepaald. Mechanistisch onderzochten we de effecten van blootstelling aan hypoxie op glucoseopname, gen- en eiwitexpressie in primaire humane adipocyten en myotubes. We toonden aan dat $\mathrm{MIH}$-blootstelling de systemische $\mathrm{O}_{2}$-verzadiging en $\mathrm{pO}_{2}$, in zowel vet- als skeletspierweefsel, verlaagde. Bovendien hebben we aangetoond dat blootstelling aan $\mathrm{MIH}$ de oxidatie van koolhydraten in het hele lichaam verhoogde met gelijktijdige verhoogde plasmalactaatconcentraties in vergelijking met blootstelling aan normoxie. Bovendien vonden we verhoogde genexpressie van verschillende routes die verband houden met inflammatie en het metabolisme van koolhydraten / lipiden in vetweefsel. MIH veranderde de mitochondriële respiratie / oxidatieve capaciteit van de SM niet, noch had het invloed op de vetweefsel, hepatische en perifere insulinegevoeligheid. Mechanistisch hebben we aangetoond dat blootstelling aan hypoxie de insuline-onafhankelijke glucoseopname in primaire humane myotubes aanzienlijk verhoogde, die op zijn minst gedeeltelijk lijkt te worden gemedieerd door AMP-afhankelijke proteïnekinase (AMPK). Dit effect werd echter niet geobserveerd in primaire humane adipocyten.

Omdatisaangetoond datexperimenteleblootstellingaanhypoxieverschillende onderliggende routes beïnvloedt die betrokken zijn bij het energiemetabolisme, onderzochten we vervolgens de effecten van $\mathrm{MIH}$-blootstelling op het vetweefselproteoom in Hoofdstuk 4. Abdominale subcutane vetweefselbiopsieën werden afgenomen na 7 opeenvolgende dagen van $\mathrm{MIH}$-blootstelling onder normoxisch, gevaste condities, in de gerandomiseerde cross-over studie. Na proteïne-isolatie werden proteïnen geïdentificeerd en gekwantificeerd met behulp van vloeistofchromatografie-massaspectrometrie. Na correctie voor bloedeiwitverontreiniging werden 1022 AT-eiwitten geïdentificeerd, waarvan 123 differentieel tot expressie werden gebracht in vergelijking met normoxie. $\mathrm{MIH}-$ blootstelling verhoogde de expressie verschillende eiwitten gerelateerd aan focale adhesie, actine-cytoskelet-organisatie en ijzerhomeostase, terwijl het de expressie van eiwitten gerelateerd aan de biosynthese van polysachariden, collageenfibrilorganisatie en NAD+-afhankelijke processen verminderde. Interessant is dat onder de laatste centrale metabole routes zijn, zoals de citroenzuurcyclus, waardoor mogelijk alternatieve routes voor energieopbrengst onder mild hypoxische omstandigheden worden bevorderd. Bovendien vonden we dat een verhoogde tropomoduline-3 (TMOD3) -expressie geassocieerd was met $\mathrm{MIH}$-geïnduceerde veranderingen in insulinegevoeligheid van het vetweefsel. Reeds is aangetoond dat TMOD3 betrokken is bij de transductie van insulinesignalen in het vetweefsel.

In Hoofdstuk 3 laten we zien dat blootstelling aan $\mathrm{MIH}$ de skeletspier $\mathrm{pO}_{2}$ substantieel verlaagde, een fenomeen dat ook wordt waargenomen bij SM contractie tijdens lichamelijke inspanning. Door inspanning geïnduceerde skeletspiercontractie bevordert de secretie van myokines, wat de opname van 
glucose en vetzuuroxidatie in het skeletspierweefsel kan verbeteren. Aangezien zowel MIH-blootstelling als skeletspiercontractie de skeletspier $\mathrm{pO}_{2}$ substantieel verlagen, wilden we onderzoeken of $\mathrm{MlH}$-blootstelling de myokinesecretie beïnvloedt in Hoofdstuk 5. Daarom werden gedifferentieerde primaire humane myotubes blootgesteld aan $1 \% \mathrm{O}_{2}$ (nabootsing van fysiologische hypoxie in skeletspierweefsel), 3\% $\mathrm{O}_{2}$. (Fysiologische normoxie in skeletspierweefsel) en $21 \% \mathrm{O}_{2}$ (standaard laboratoriumomstandigheden) gedurende 24 uur. Vervolgens werd celmedium verzameld voor myokine analyse. Verder bepaalden we plasmaconcentraties van verschillende myokines bij personen met overgewicht en obesitas die 7 opeenvolgende dagen waren blootgesteld aan normobare $\mathrm{MIH}$ tijdens een maaltijdtest onder hypoxische omstandigheden (op dag 7) en onder normoxische omstandigheden (op dag 8, ongeveer 16 uur na laatste hypoxische stimulus), in een gerandomiseerde cross-over studie. We toonden aan dat in vitro blootstelling aan hypoxie $\left(1 \% \mathrm{O}_{2}\right)$ de secretie van myokines veranderde. Van deze myokines wordt gesuggereerd dat ze betrokken zijn bij glucosehomeostase, waarbij hypoxie mogelijk een rol speelt als modulator van myokinesecretie. In vitro blootstelling aan hypoxie verhoogde de secreted protein, acidic and rich in cysteine (SPARC) en follistatin-related protein-1 (FSTL-1) expressie, terwijl het de expressie van leukemia inhibitory factor (LIF) verminderde in vergelijking met $3 \% \mathrm{O}_{2}$. 7-daagse $\mathrm{MIH}$ veranderde de plasma myokine concentraties echter niet tijdens (op dag 7) en volgend op (op dag 8) het blootstellingsregime bij mannen met overgewicht en obesitas.

Studiesophogehoogtesuggererendatblootstellingaanhypoxieveranderingen in de samenstelling van de darmflora zou kunnen veroorzaken, die op hun beurt het metabolisme van de gastheer kunnen beïnvloeden. Echter, gecontroleerde studies ontbreken in de huidige literatuur. Daarom onderzochten we in Hoofdstuk 6 de effecten van normobare $\mathrm{MIH}$-expressie $\left(15 \% \mathrm{O}_{2}, 3 \times 2\right.$ uur per dag, 7 opeenvolgende dagen) vergeleken met normoxie $\left(21 \% \mathrm{O}_{2}\right)$ op de samenstelling van de darmflora bij mannen met overgewicht en obesitas. Met behulp van $16 \mathrm{~S}$ rRNA-genampliconsequencing hebben we aangetoond dat blootstelling aan $\mathrm{MIH}$ bescheiden veranderingen in de samenstelling van de fecale microbiota veroorzaakte bij mensen met overgewicht en obesitas, waardoor verschillende bacteriële families en geslachten verschoven naar hogere abundantie van strikt anaerobe butyraatproducerende bacteriën. Bovendien hebben we aangetoond dat verschillende van deze door $\mathrm{MIH}$ geïnduceerde effecten op de microbiële samenstelling verband hielden met parameters van glucose- en lipidenmetabolisme.

Omdat hypoxie-geïnduceerde effecten op glucosehomeostase mogelijk vergelijkbare onderliggende mechanismen zou kunnen delen in vergelijking met lichaamsbeweging, hebben we vervolgens het synergetische potentieel van hypoxie en lichaamsbeweging onderzocht. Daarom hebben we een enkelblinde. gerandomiseerde, cross-over studie uitgevoerd om de effecten van hypoxische 
inspanning $(\mathrm{HI})$, op matige intensiteit, op glucosehomeostase bij mensen met overgewicht en obesitas met verminderde glucosehomeostase te onderzoeken in Hoofdstuk 7. Tien deelnemers fietsten op matige intensiteit, gedurende 4 opeenvolgende dagen, onder milde normobare hypoxie $\left(\mathrm{FiO}_{2}: 15 \%\right)$ of normoxie ( $\mathrm{FiO}_{2}: 21 \%$ ) bij vergelijkbare relatieve trainingsintensiteit (2×30 min / d bij 50\% van de maximale hartslag $\left(\mathrm{HR}_{\mathrm{MAX}}\right)$ of $\left.50 \% \mathrm{~W}_{\text {MAX }}\right)$, met een uitwasperiode van 3-6 weken. Gedurende het onderzoek werden 24-uurs glucoseconcentraties en systemische $\mathrm{O}_{2}$ saturatie gevolgd. Op dag 5 werd onder normoxische omstandigheden het substraatmetabolisme onderzocht. Middels deze studie hebben we aangetoond dat $\mathrm{HI}$ bij een vergelijkbare relatieve intensiteit van de inspanningsbelasting in vergelijking met normoxie, de systemische $\mathrm{O}_{2}$ saturatie verminderde in vergelijking met normoxische inspanning. Echter, inspanning onder hypoxische condities veranderde de gemiddelde glucoseconcentraties over 24 uur, overdag en 's nachts niet. Tevens bleven verschillende parameters welke de glycemische variabiliteit omvatten ongewijzigd. Desalniettemin was de vermindering van de systemische $\mathrm{O}_{2}$ saturatie door $\mathrm{HI}$ positief gecorreleerd met door $\mathrm{HI}$ geïnduceerde verandering in de gemiddelde glucoseconcentraties gedurende 24 uur en overdag

De belangrijkste bevindingen van dit proefschrift tonen aan dat $\mathrm{MIH}$ de weefselspecifieke insulinegevoeligheid niet veranderde. Zowel in vivo als in vitro onderzoeken tonen echter effecten aan op substraatmetabolisme, wijzend op een verhoogd glycolytisch metabolisme. Bovendien veranderde hypoxische inspanning de glucosehomeostase niet bij mannen met overgewicht en obesitas met een verstoord glucosemetabolisme. Toekomstige studies zijn essentieel om het potentieel van verschillende hypoxische blootstellingsregimes te onderzoeken, met inachtneming van de duur, frequentie en intensiteit van de hypoxische stimulus, teneinde metabole aanpassingen te induceren. Het loont de moeite om dit bij mannen en vrouwen afzonderlijk te onderzoeken, en om de effecten van blootstelling aan hypoxie te onderzoeken in studiepopulaties met een ander metabool en inflammatoir fenotype. Indien blootstelling aan hypoxie gunstige effecten lijkt te hebben, kan dit een nieuwe therapeutische strategie zijn om obesitas-gerelateerde complicaties te voorkomen of te behandelen. 